\title{
Impact theory under fire once more
}

Independent studies are casting more doubt on a controversial theory that a comet exploded over North America nearly 13,000 years ago, wiping out the Clovis people and many of the continent's large animals.

Archaeologists have examined sediments at seven Clovis-age sites across the United States, and found that the concentration of magnetic debris was insufficient to confirm an extraterrestrial impact at that time, says a report in the Proceedings of the National Academy of Sciences (PNAS) ${ }^{1}$.

In 2007, a team led by Californian researchers proposed that a comet or asteroid had exploded over the North American ice sheet, creating widespread fire and an atmospheric soot burst followed by a cooling period known as the Younger Dryas ${ }^{2}$.

Sometime after this, the Clovis people, largeanimal hunters known for their spear points, mysteriously disappeared.

Key evidence for the purported impact was magnetic microspherules discovered in sediments at 25 locations. Richard Firestone, of Lawrence Berkeley National Laboratory in California, and his colleagues argued that the microspherules were cosmic debris from an explosion. But in more than 18 months of sedimentary analysis, a team led by Todd Surovell, an archaeologist at the University of Wyoming in Laramie, was unable to detect high levels of microspherules at any of the sites, including two where Firestone's team had reported finding them.

"I spent hundreds of hours at the microscope examining sediment samples," says Surovell, "and I didn't find any physical evidence to support their theory."

The other team isn't backing down. "Their study doesn't negate our hypothesis," says James Kennett, a palaeoceanographer at the University of California, Santa Barbara, and one of Firestone's co-authors. Another co-author, geophysicist Allen West of Prescott, Arizona, says that Surovell's group didn't use the correct techniques to extract, identify and quantify the microspherules.

In a PNAS article published $^{3}$ in February, Jennifer Marlon, a doctoral geography student and her colleagues found no evidence of systematic burning of biomass - as would have occurred if continent-wide fires had happened - at the time of the Younger Dryas in pollen and charcoal records at 35 sites. Rex Dalton

1. Surovell, T. A. et al. Proc. Natl Acad. Sci. USA advance online publication doi:10.1073/pnas.0907857106 (2009).

2. Firestone, R. B. et al. Proc. Natl Acad. Sci. USA 104 16016-16021 (2007).

3. Marlon, J. R. et al. Proc. Natl Acad. Sci. USA 106, 2519-2524 (2009).

For more, see go.nature.com/kWeeKL 